\title{
Effective Leadership Conceptualization in Higher Education Context
}

\author{
Sobia Shafaq Shah ${ }^{1}$, Asif Ali Shah ${ }^{2}$, Arjumand Bano Soomro ${ }^{3}$
}

\begin{abstract}
The relevancy and significance of effective leadership has been emphasised in every setting, situation and context. The conceptualisation of effective leadership embedded in multiple perspectives due to the contextualised nature of leadership. The significance of higher education institutions and the necessity to manifest effective leadership in educational context entails empirical research and deep down understanding. Keeping in view the elusive nature of effective leadership and pivotal role of department head, this research endeavour aimed at exploring faculty members' perceptions concerning their conceptualisation of effective department leadership. Drawn from inductive research approach, semi-structured interviews were conducted from twelve faculty members of public university of Pakistan, located in Sindh province. The study findings highlighted thirteen important behaviours in relation to manifesting effective leadership by department heads. Notably, the majority of highlighted leadership behaviours appeared closely aligned with various dimensions of transformational leadership. However, there is need to conduct further research studies with larger sample size to endorse the effective leadership conceptualisation in Pakistani higher education context.
\end{abstract}

Keywords: Effective leadership, Higher education, Department heads, Faculty members, Public university

JEL Code: I12, J53, M12

\section{Introduction}

The core concept that underpins the leadership notion relates to influencing and facilitating individuals and organisations to attain their desired goal. Effective leaders have been conceptualised as those who can work well with their team members in shaping collective efforts to achieve institutional goals (Nahavandi, 2015, Bolden 2016). In order to refine this conceptualisation, leadership researchers strove to identify particular aspects of leadership behaviour that could elucidate effective leadership. The relevancy of effective leadership has been emphasised in every situation and context (Bass, 2008). This large emphasis on leadership can be attributed to the notion that effective leaders can initiate a positive interaction with their followers, can develop a

${ }^{1}$ IBA, University of Sindh, Jamshoro, Pakistan

${ }^{2}$ Mehran University of Engineering and Technology. Jamshoro, Pakistan

${ }^{3}$ IICT University of Sindh, Jamshoro

Corresponding Author: sobia.shah@usindh.edu.pk 
conducive working environment and can deal with the multiple challenges posited by external forces (Nahavandi, 2015) to produce quantitatively and qualitatively high results (Bass, 2008).

Notably, transformational leadership has been conceptualised in relation to effective leadership within Western developed countries (McCaffery, 2010; Smothers et al., 2012; Yukl, 2012). However, it has been pointed out that the "leadership effectiveness is profoundly influenced by the context" within which the leadership phenomenon takes place (Bryman and Lilley, 2009, p.337). The emphasis on effective leadership in academic settings is echoed at national as well as global level, due to the central role played by the higher education in the economic development of a country (Kim, 2011). The emergence of multifarious challenges faced by the academic sector, the significance of higher education institutions and the demand for effective leadership have changed the overall scenario in which universities need to operate, managed and led (Northouse, 2013).

Within the hierarchical structure of public universities in Pakistan, formal authority flows from top to bottom (i.e., vice-chancellor to pro-vice-chancellor, pro-vicechancellor to deans of faculties, and then deans of faculties to heads of departments/institutes/centres). Each department/institute/centre is headed by a chairperson/director (the department head) who is responsible for the entire academic, research and administrative matters of the subordinate faculty and respective departments/institutes/centres. The role of a department head has been referred to as being very important and, irrespective of the country, this leadership position has been considered of significant value (Smothers et al., 2012). Generally, the department leadership position has been characterised as a middle position within the academic setting, although Middlehurst (1995) stresses that due to the distinctive nature of higher education settings and the pivotal role of department leadership, this position cannot be directly compared with the middle management position in non-academic or private sector settings.

In order to characterise effective department leadership, an awareness of the faculty members' perceptions of desired leadership behaviour would be of significant value for the department heads (Aktas et al. 2016). There is nearly universal consensus that the leadership is a function of leaders and followers, embedded in a rich web of negotiated meanings and contextual variables" (Bligh et al., 2004, p.562). This refers to the way that followers conceptualise effective department leadership, which in turn is likely to identify the characteristics that could exert a positive impact on individuals as well as organisational outcomes (Smothers et al., 2012). Currently, Higher Education Commission (HEC) of Pakistan urges faculty members to play a more active role by adopting innovative and performance-oriented approaches to teaching, research, consultancy, publication of books and journal articles, development of entrepreneurial activities and community involvement. Such multiple expectations from faculty members entail positive leader-faculty interaction, established through socio-cultural and contextual-driven leadership practices, to achieve institutional goals drawn from individual and group performances.

It is of note that despite a high value being attached to the role of department head pertinent to developing direct and frequent interaction with the faculty members and

Sukkur IBA Journal of Management and Business - SIJMB | Vol 8 No. 1 January - June 2021 
monitoring the core functions of teaching and research, little attention has been paid to investigate how this leadership position is practised within academic settings (Mushtaq and Akhtar, 2014). In order to address this research gap, by employing an inductive research strategy, this research study intends to offer a contextualized understanding of effective leadership by obtaining a subjective interpretation of the faculty members' opinions regarding their conceptualisation of effective leadership within their own work settings. In this regard, this research is focused on addressing research question concerning "Which aspects of the leader behaviours or approaches are allied with effective leadership at the department level in the context of a Pakistani public university, from the faculty members' perspective?".

The contribution of this research study to the extant literature concerning departmental leadership is threefold. First, this research study is the first attempt to employ inductive approach to explore faculty members' subjective perceptions to gain deeper and through understanding pertinent to departmental leadership. Second, this study tried to unfold the contextualised nature of the departmental leadership in higher education context. Third, this research used well tested leadership frameworks to build upon effective leadership conceptualisation at departmental level.

\section{Literature Review}

In ascertaining effective leadership, the emergence of numerous types of leadership behaviour within the relevant studies has made it challenging to compare and integrate the findings concerning effective leadership conceptualisation (Bass, 2008). However, this challenge endorses that there is a need to take into account multiple perspectives and approaches with respect to effective leadership conceptualisation. Following this perspective, Yukl (2012) conducted an extensive literature review, spread over more than half of a century, to identify various aspects of leadership behaviour associated with effective leadership conceptualisation. Drawn from his analysis, Yukl pointed out certain aspects of leadership behaviour and classifies them into four main dimensions. According to Yukl's (2012) conceptualisation, task-oriented behaviour is characterised in terms of accomplishing work in an efficient and reliable manner by employing people, equipment and other resources, and it constitutes sub-dimensions of clarifying, planning, monitoring operations and problem-solving. According to Yukl's (2012) classification, relation-oriented behaviour places emphasis on developing a positive interaction between leaders and subordinates, by supporting, developing, recognising and empowering subordinates. Yukl (2012) describes change-oriented behaviour in relation to enhancing innovation, promoting collective learning and adapting external changes by exercising sub-dimensions of advocating change, envisioning change, encouraging innovation and facilitating collective learning. Moreover, concerning effective leadership, Yukl (2012) identifies the external behaviour of a leader in terms of fostering and sustaining external links though networking, external monitoring and representing.

Moreover, Yukl stresses that the timing of when to exercise particular leadership behaviour is also of significant value, because when problems are timely addressed, then this is more effective than waiting until the issues turn very serious. This suggests that although the demonstration of certain sets of behaviour is important, sometimes it 
is essential for a leader to find an appropriate balance among them that seems contradictory to each other, such as directing versus empowering (Kaiser and Overfield, 2010).This reflects that a leader's ability to practise a variety of leadership behaviours and to match them with underlying situations (in other words, 'behavioural flexibility') is also associated with effective leadership (Yukl and Mahsud, 2010).

Yukl (2012) highlights that the fifteen aspects of leadership behaviour concerning effective leadership, identified through an extensive literature review, appear closely aligned with the transformational and transactional leadership framework. Here, individualised consideration entails supporting and developing, inspirational motivation involves envisioning change, intellectual stimulation involves encouraging innovation, and idealised influence is mainly referred to as a measure of the perceived integrity of the leader, demonstrated by maintaining consistency between the leader's actions and adopted values (Yukl, 2012 ).On the other hand, transactional leadership involves one task-oriented behaviour (such as monitoring), one relation-oriented behaviour (such as recognising) and communication of reward (Yukl, 2012).

McCaffery (2010) highlights that despite the fact that substantive research to date has focused upon exploring the attributes of effective leadership within higher education settings, "the quest to determine just what makes a leader effective...remains as elusive today as it has ever been" (McCaffery, 2010, p.82). To address this concern, McCaffery elaborates upon four models of new leadership: the visionary leader, the learning organisation leader, the liberating leader and the discretionary leader, all pertinent to effective leadership conceptualisation. Notably, these four models of new leadership draw heavily from transformational leadership in relation to elaborating contemporary thinking concerning effective leadership (McCaffery, 2010,).

On the whole, McCaffery's conceptualisation of effective leadership involves vision, empowerment, continuous learning, development, unlocking potential, encouraging creative activities and endorsing leaders' discretionary roles pertinent to outlining particular types of behaviour to reflect effective leadership. Notably, all these aspects have significant relevance within the higher education context and could provide useful insights concerning effective leadership in an academic setting. It is of note that McCaffery's (2010) conceptualisation involves effective leadership across all hierarchical levels within higher education settings, whereas in some studies, effective leadership has also been conceptualised specifically at department level within academic settings.

With respect to exploring effective leadership at department level, Bryman (2007) reviewed extensive literature drawn from studies conducted within the UK, USA and Australian academic contexts. Based on his analysis, he identified various aspects of leadership behaviour related to effective leadership conceptualisation at department level. In the prior literature, these aspects of leadership behaviour were characterised from different perspectives. In this regard, leadership behaviour entailing due consideration in relation to offering due respect so as to develop mutual trust has been considered as an important aspect of effective leadership within higher education settings (Abuorabl, 2012). In a similar vein, the leader has been characterised as a visionary, as one who offers a roadmap to subordinates to show the direction that the department is expected to go and communicate a shared vision of the department

Sukkur IBA Journal of Management and Business - SIJMB | Vol 8 No. 1 January - June 2021 
(Bryman, 2007). Concerning this aspect, a number of previous studies have corroborated the significance of promoting a shared vision by the leader within higher education settings (Asaari, 2012).

Although, drawn from the literature review, Bryman (2007) proposes a list of thirteen aspects of leadership behaviour in relation to conceptualisation of effective department leadership. However, he also raises the significance of particular context, while exercising these proposed aspects of behaviour by the leader. In this regard, Bryman (2007) argues that the notion of context and situational diversity could exert notable influence on implications of effective leadership, so leadership behaviour that might appear effective in one context may not work effectively in another setting. Pertinent to effective leadership conceptualisation in higher education settings, the professional/intellectual status of academic staff has also emerged as an important consideration, whilst identifying the manner by which faculty members may need to be led (Kok and McDonald, 2017).

Bryman and Lilley (2009) attempted to explore academics' views concerning the basic notion of effective leadership at department level. Interestingly, they reported that the majority of the behavioural patterns which emerged from the interview findings concerning effective leadership were consistent with the major themes identified by Bryman (2007). Moreover, Bryman and Lilley (2009) characterised the department head's position as 'stuck in the middle' in terms of representing the university to the department on one side and department to the university on the other. Due to this middle position, Gmelch (2004) refers to this leadership position in terms of having broader institutional requirements and expectations of the institutional leaders on the one hand, and of the expectations and needs of their departmental staff on the other hand.

The above discussion reveals that the effective leadership conceptualisation draws impetus from different perspectives. In broader terms, Yukl (2012) terms his effective leadership conceptualisation as being closely aligned with transformational and transactional leadership. In a similar vein, McCaffery (2010) describes effective leadership within the framework of four models of new leadership, which are heavily drawn on transformational leadership. On the whole, it is of note that whatever aspects of leadership behaviour concerning effective leadership conceptualisation have been debated within relevant literature, their implications are predominantly elaborated upon and linked with contextualised understanding. This strong emphasis on contextualised understanding raises a need to understand effective leadership within that particular context (i.e., where it takes place).

\section{Methodology}

In terms of acknowledging the distinctiveness of human nature, as well as measuring social phenomena using qualitative research, the interpretive approach appears to be necessary to understand the subjective meanings assigned to social actions by individuals (Bryman, 2012). The focus of this research study is based on seeking the perceptions and opinions of the faculty members of a particular public university in Pakistan. The selected public university in Pakistan, which is the focus of this research is located in Jamshoro city and is one of the oldest and largest in this country. It comprises one main campus and seven other campuses in different cities. Since the

Sukkur IBA Journal of Management and Business - SIJMB | Vol 8 No. 1 January - June 2021 
qualitative research is mainly aimed at explaining a particular phenomenon or specific concept, therefore the researcher commonly selects a small sample which could provide detailed insight regarding the research issue under study. Consequently, in qualitative research, instead of focusing on generalisation, the detailed understanding of a few individuals is preferred (Creswell and Plano Clark, 2011).

For qualitative data collection, permanent faculty members of one large public sector university with minimum two year working experience were contacted for their voluntary participation in the research. The selection of permanent faculty members is based on the rationale that these faculty members had much involvement with ongoing activities at department level and have certain experiences/expectations from their departmental leadership. Initially, twenty-five faculty members were contacted. The total seventeen faculty members expressed their willingness to participate. However, keeping in view, the objectives of the study and nature of the purposive sampling twelve faculty members were selected for semi-structured interview. Among these twelve faculty members, eight were selected from the main campus and four were selected from the other campuses. The rationale behind the selection of eight members from the main campus and four from the other campuses was based upon the notion that faculty members from both the main campus and the other campuses would collectively provide a more comprehensive and deeper account of the issue under study. The selection of twelve faculty members for semi-structured interviews offered the opportunity to obtain an in-depth and detailed insight pertinent to the issue under study in the best possible way (Bryman, 2012).

The data were analysed through "thematic analysis" by using NVivo 10 (QSR International PT, 2014). The use of 'thematic analysis' appeared suitable in relation to exploring the similarities and inconsistencies across the participants' responses, which could enable the researcher to organise, summarise and report the main contents and the underlying pattern of the data under pre-defined as well as new emerging themes, reflected by the empirical data (Bryman, 2012). Drawn from the general guidelines proposed by Creswell (2012) concerning qualitative data analysis, all semi-structured interviews were transcribed, coded, categorised, thematized, analysed and interpreted in terms of achieving the research objectives.

\section{Data Analysis}

This section presents the qualitative data analysis and findings concerning research question: "Which aspects of the leader behaviours or approaches are allied with effective leadership at the departmental level in the context of a Pakistani public university, from the faculty members' perspective?". In terms of initiating the data analysis, inductively and deductively constructed codes were generated from the qualitative data, then later on these codes were grouped and categorised into thirteen themes as encapsulated in Table 1 and elaborated below: 
Table 1: Desired Behaviours to Effective Leadership at Department Level

\begin{tabular}{|l|}
\hline Offering fair treatment \\
\hline Providing guidance and supervision \\
\hline Providing support and mentoring \\
\hline Permitting participation in decision making \\
\hline Maintaining mutual trust and due respect \\
\hline Promoting teamwork and collegiality \\
\hline Communicating effectively on department issues \\
\hline Acting as a role model \\
\hline Adopting a proactive approach \\
\hline Advancing personal and promotional development \\
\hline Adjusting workload to enhance performance \\
\hline Managing limitations constructively \\
\hline
\end{tabular}

Source: This study

\subsection{Offering Fair Treatment}

A common view amongst the participants concerned the significance of the leaders' behaviour aimed at offering fair treatment to all faculty members. Participants elaborated upon the fair treatment shown by the leaders in relation to providing equal opportunities, fair allocation of workload and fair implementation of rules and policies. On the whole, conversations with the interview participants noted that, for faculty members, receiving fair treatment by the leader is of utmost value, whereas any leader's behaviour that caused feelings of unfair treatment among faculty members could have a negative impact on them. Due to such a strong emphasis being placed on fair treatment, this aspect of leader behaviour emerged as a core aspect of faculty members' conceptualisation of effective department leadership.

\subsection{Providing Guidance and Supervision}

The guidance and supervision provided by a leader emerged as an integral aspect of effective leadership conceptualisation. The participants strongly supported this aspect of leader behaviour in relation to the multidimensional nature of the faculty job. The participants maintained that because they have to work on multiple tasks and are required to fulfil different deadlines, they expect that their leaders would make efforts to ensure that the multiple activities are well planned and well-coordinated, so that faculty members could perform them in the best possible way. Overall, the conversations with the participants noted that conceptualisation of effective leadership draws impetus from a leader's willingness to sort out underlying problems in the best possible manner, minimising work disruptions and nurturing positive relationships between faculty members and the leader, as well as among the faculty members themselves.

\subsection{Employing a Problem-solving Approach}

Employing an effective problem-solving approach by a leader emerged as the most cited behaviour by the participants with reference to effective leadership conceptualisation. 
The participants characterised the image of an effective leader as being a problem solver, considering that the occurrence of problems is normal in any working environment. However, a conducive work environment primarily determined by the manner by which a leader would resolve these problems. The participants raised the necessity of problem-sharing with the leader to make him/her well aware of existing problems. The participants criticised leadership behaviour incorporating negative problem-solving approach by ignoring the signs of emerging problems, making hasty responses before knowing the actual cause of a problem, and taking too much time to take decisions so that the matter becomes more complicated.

\subsection{Providing Support and Mentoring}

The significance of support and mentoring provided by the leader was highlighted by eleven majority participants. Concerning this aspect, the participants characterised effective leadership in relation to the actions taken by a leader to help faculty members perform well on difficult tasks by expressing confidence in their abilities and achievements. Primarily, this aspect of leadership behaviour was characterised in terms of offering psychological safety and positive backing to faculty members, to enable them to learn from their mistakes and failures, instead of becoming afraid in any undesirable situation. In broader terms, the participants strongly advocated leadership behaviour which was aimed at promoting a 'can do' attitude amongst faculty members, in relation to enhancing their self-confidence and providing constructive feedback on their performance. On the whole, it was noted that, for faculty members, gaining support from their leader and the leader's role as a mentor, constituted important aspects in the conceptualisation of an effective leader.

\subsection{Permitting Participation in Decision-making}

The participants identified the significance of leadership behaviour aimed at promoting faculty members' participation in decision-making, in terms of manifesting effective leadership. In this regard, a common view amongst the participants was that because routine decisions are more often taken at department level pertinent to daily work activities, faculty members' participation in decision-making could make them more familiar with existing issues. Overall, the conversations with the interview participants noted that, for faculty members, effective department leadership conceptualisation was embedded in the opportunities available for them to participate in decision-making. Primarily, amongst the participants, the highly educated status of the faculty members and the nature of departmental decision-making in terms of incorporating daily work activities, were the key factors pertinent to supporting their involvement in decisionmaking.

\subsection{Maintaining Mutual Trust and Due Respect}

The participants raised the importance of leadership behaviour aimed at promoting mutual trust and offering due respect by promoting collaboration and positive interaction between the leader and faculty members. Essentially, the conversations with the interview participants identified that the reciprocal nature of mutual trust and due respect plays an important role in manifesting effective leadership, by enhancing faculty 
members' confidence that their efforts will achieve desired outcomes, which would be beneficial for all.

\subsection{Promoting Teamwork and Collegiality}

The participants asserted that the leader's behaviour towards promoting teamwork and collegiality could positively contribute to a conducive working environment. The participants referred to teamwork in terms of exerting collective efforts to achieve common tasks, whereas collegiality was elaborated upon in terms of providing mutual support to each other within the academic setting. In terms of emphasising the significance of this aspect of leadership behaviour, the participants expressed that because they are expected to be engaged in individual as well as joint tasks, the working environment is therefore largely shaped by mutual cooperation and collective learning. Overall, the participants were of the view that a high degree of teamwork spirit and collegiality could be considered as a reflection of practising effective leadership by the department leader.

\subsection{Communicating Effectively on Departmental Issues}

The participants emphasised the significance of a leader's behaviour aimed at ensuring effective communication within and outside the department, in terms of raising and addressing departmental issues. A common view amongst the participants was that departmental leadership entails direct and frequent interaction with faculty members as well as with the higher authorities. Therefore, the leader could utilise this leadership position as a bridge between the two sides and could exchange important information to both sides of the bridge. The participants identified effective internal communication by the department leader in terms of clearly defining work responsibilities, setting priorities and deadlines, and promoting familiarity with formal rules, policies and performance measurement standards. On the whole, faculty members characterised an effective leader as one who made efforts to facilitate the vertical communication flow between higher-ups and faculty members, as well as the horizontal communication flow among all departmental members themselves.

\subsection{Acting as a Role Model}

Participants pointed out that a leader demonstrating desirable behaviour could work effectively, instead of relying solely upon written policies and procedures. Primarily, participants were of the view that the leader should set an example to others by demonstrating desired behaviour in relation to policy compliance, civility, trust, selfefficacy and self-confidence. However, in terms of debating the role model aspect of a leader's behaviour, the participants acknowledged the intellectual status and professional exposure of the faculty members and suggested that the leader should adopt a distinctive approach while demonstrating desired behaviour. The participants' emphasised that the department leader, being academic like other faculty members, should not focus on the traditional subordinate-leader relationship in an academic setting. Instead, the leader should establish credibility among faculty members as an academic and shouldtry to gain the desired behaviour from them by modelling their

Sukkur IBA Journal of Management and Business - SIJMB | Vol 8 No. 1 January - June 2021 
own behaviour first. The participants believe that the moral values maintained by a leader could act as a basic source for the leader's influence upon faculty members.

\subsection{Adopting a Proactive Approach}

Participants pointed out the significance of leadership behaviour aimed at adopting a proactive approach, in relation to assessing an emerging situation and taking actions to contribute positively in every situation. Primarily, participants characterised an effective leader as a proactive one, who takes the initiative to find solutions to problems rather than just focusing on reporting the problems. The participants characterised a proactive leader as an effective leader in terms of timely decision-making, ensuring a smooth working environment and avoiding unnecessary delays. On the whole, the participants were of the view that the conceptualisation of effective leadership draws impetus from using a proactive approach, because for certain issues the immediate attention of a leader is needed, especially where a delayed response to these problems could not yield better results.

\subsection{Advancing Personal and Professional Development}

A common view amongst participants concerned the significance of a leader's behaviour which aimed at enhancing personal and professional development of faculty members by offering them various opportunities, either within or beyond the university. The participants emphasised this aspect of leadership behaviour in relation to the distinctive nature of higher education institutions pertinent to the production and dissemination of knowledge, which entails maximum opportunities for the personal and professional development of faculty members. Related to this aspect of leadership behaviour, the participants raised the issue of the lack of sufficient funding allocated for their higher education and research work. The participants also appreciated their leader's behaviour aimed at encouraging innovative approaches to be used by the faculty members. Overall, the conversations with the participants reflected the leaders' efforts in relation to promoting various activities that could enhance the personal and professional development of faculty members, which constitute a fundamental aspect of effective leadership conceptualisation.

\subsection{Adjusting Workload to Enhance Performance}

The participant pointed out the significance of leadership behaviour which helps faculty members by providing them with the required resources and fine-tunes their workload. The participants attributed the relevancy of this aspect of leadership behaviour to their multifaceted nature of their job, in relation to academic teaching, research, administration, student advising etc., which demands specific types of resources, expertise and aptitudes. Participants highlighted the issue of less research productivity due to their heavy teaching workload. Overall, the conversations with the participants indicated that the conceptualisation of effective leadership is largely also embedded in the leaders' efforts aimed at facilitating faculty members by providing them with the necessary resources, safeguarding them from unnecessarily heavy workloads and enhancing their productivity.

Sukkur IBA Journal of Management and Business - SIJMB | Vol 8 No. 1 January - June 2021 


\subsection{Managing Limitations Constructively}

Primarily, the participants proposed that the leader should adopt a more effective approach in terms of dealing with various issues, because although there were some issues which the leader could deal with himself/ herself, for some other issues the involvement of higher authorities was needed. The participants considered that the leader should utilise his/her middle position more effectively, by paying individual attention to each faculty member and appropriately communicating their matters to the higher authorities. Mainly, the participants were of the view that the leader, by enhancing his/her referent power, could reasonably offset the limitations of their official authority. The participants conceptualised the department leadership position in terms of representing their departments in transactions with insiders and outsiders, due to which their position not only entails lobbying for the required resources, but also is expected to promote and defend the reputation of the department, by negotiating agreements and coordinating relevant activities.

\section{Discussion and Conclusion}

The overall findings broadly appear consistent with the conceptualisations of effective leadership proposed by Bryman (2007), McCaffery (2011). The various aspects of behaviour relating to effective leadership identified in this research study are also documented in the prior empirical research (for example, Hardre et al., 2011; Kim, 2011; Toker, 2011; Abuorabl, 2012; Amin, 2012, Amzat and Idrees,2012; Asaari, 2012; Kalargyrou et al., 2012, Smothers et al., 2012, Burhanuddin, 2013, Giziri, 2014). However, the research study findings appear unique in that they need to be understood from the individual's perspective based on their subjective interpretation. Because Yukl (2012) stressed that the behaviour constructs are basically conceptual tools and there is no objective reality for them. Consistent with Yukl's argument, while shedding light on different aspects of effective leadership conceptualisation, faculty members elaborated upon their perspectives in a distinctive manner, drawn from their personal experiences and individual preferences.

With regard to endorsing the significance of the contextualised understanding of leadership practices, this study acknowledges that if leadership is isolated from its context, then ambiguities might arise pertinent to defining effective leadership in any setting. Therefore, it is rational to believe that those desirable leadership practices highlighted by the faculty members concerning effective leadership are influenced by the underlying context of public sector university of Pakistan. Notably, with regard to this study's findings, there is the need to acknowledge that those leaders who demonstrate the aforementioned thirteen aspects of leadership behaviour, as emphasised by the faculty members (or a large number of them), are more likely to be considered effective leaders by their faculty members than those leaders who do not demonstrate them. However, it is important to bear in mind that these thirteen aspects of leadership behaviour emerged from the subjective interpretations of the study participants. They do not necessarily embrace any prescribed list of fixed behaviour required for practicing effective leadership.

This study corroborates Bryman and Lilley's (2009) argument that "leadership effectiveness is profoundly influenced by the context, within which leadership 
phenomenon takes place" (p.337). In addition, this study's findings are consistent with those of Bush and Middlewood (2005), who claim that organisational culture is an important component of a specific context, where leader and faculty members interact with each other, and consequently it could offer an immediate framework for their actions. With reference to this research, in broader terms, the organisational culture of the public university under study might be reflected by its semi-autonomous status, organisational hierarchy, working practices and conventions, rules, regulations, policies, procedures and operating systems, as well as its demographic features, which might vary from those of other institutions.

Interestingly, this study demonstrates that the various aspects of leadership behaviour, identified with respect to effective leadership conceptualisation, appear closely aligned with the different aspects of the five dimensions of the transformational leadership style and some aspects of the transactional leadership style ('contingent reward' dimension only). In this regard, leadership behaviours comprising of 'fair treatment, guidance and supervision', 'effective problem-solving', 'support and monitoring', 'participation in decision-making', 'mutual trust and due respect', 'collegiality and teamwork', 'being a role model' and 'proactive approach', in broader terms, embrace the various aspects of the transformational leadership style. Whereas, leadership behaviours aimed at 'clear communication', 'adjusting workload' and 'providing required resources' broadly align with the 'contingent reward' dimension of the transactional leadership style.

In broader terms, this study's findings are in accord with those of Braun et al. (2013), who assert that the significance of the transformational leadership style in manifesting effective leadership within an academic setting may be attributed to the assumption that its five dimensions reflect individual as well as team-focused behaviours that positively contribute at both individual and group level. Consistent with this research study, both Yukl (2012) and McCaffery (2010) considered their effective leadership conceptualisation as being closely aligned with the different aspects of the transformational and transactional leadership styles. Overall, this study strongly supports the practice of the transformational leadership by the department heads in the public sector university under study. Notably, although this study provides useful insight pertinent to conceptualisation of effective leadership, however, some caution is needed to generalise findings. One limitation of this research is that it is confined to just one public university of Pakistan, located in the province of Sindh. Therefore, in order to validate these findings, further research is needed from both public and private universities across all of the country. Future research studies may also include departmental heads' views along with faculty members to offer more inclusive understanding of the phenomenon. Further, future studies might also employ mixed method research approach by utilising quantitative and qualitative techniques to study the multidimensional nature of leadership phenomenon.

\section{Author Contribution}

Shah, S.S: Conceptualization, Methodology, Writing-Original Draft, Supervision Shah, A.A: Methodology, Formal Analysis, Writing- Review and Editing Soomro, A.B: Formal Analysis, Writing-Review and Editing 


\section{DATA AVAILABILTY STATEMENT}

The datasets generated during and/or analyzed during the current study are available from the corresponding author on reasonable request.

\section{CONFLICT OF INTEREST}

No conflict of interest

\section{FUNDING}

No funding is received for this research project.

\section{REFERENCES}

Abuorabl.T. (2012).The impact of transformational and transactional leadership characteristics on motivation, job satisfaction and trust within Jordanian universities, (unpublished doctoral thesis), Liverpool John Moores University, United Kingdom.

Aktas, M., Gelfand, M. J., \& Hanges, P. J. (2016). Cultural tightness-looseness and perceptions of effective leadership. Journal of Cross-Cultural Psychology, 47(2), 294-309.

Amin, M., Shah, S. \& Tatlah, A. (2013).The impact of principal/directors' leadership styles on job satisfaction: perceptions of the faculty members' in a public university in Punjab, Pakistan, Journal of Research and Reflections in Education, 7 (2), pp.97-112.

Amzat, I.H. and Idris, D.A.R. (2012). Structural equation models of management and decisionmaking styles with job satisfaction of academic staff in Malaysian Research University. International Journal of Educational Management, 26 (7), pp.616-645.

Asaari, M.H. (2012).Academic leadership and work-related attitude(unpublished doctoral thesis), University of Hull, United Kingdom.

Bass, B.M. (2008). The Bass's handbook of leadership. theory, research and managerial applications.4th ed. London: The Free Press.

Bligh, M.C., Kohles, J.C. and Meindl, J.R. (2004). Charting the language of leadership: a methodological investigation of President Bush and the crisis of 9/11. Journal of Applied Psychology, 89 (3), pp.562-574.

Bolden, R. (2016). Leadership, management and organisational development. In Gower handbook of leadership and management development (pp. 143-158). Routledge.

Braun, S., Peus, C., Weisweiler, S. \& Frey, D.(2013).Transformational leadership, job satisfaction, and team performance: a multilevel mediation model of trust, The Leadership Quarterly, 24 (1), pp.270-283.

Bryman, A. (2007). Effective leadership in higher education: a literature review,Studies in Higher Education, 32 (6), pp.693-710.

Bryman, A. \& Lilley, S. (2009). Leadership researchers on leadership in higher education, Leadership, 5 (3), pp.331-346.

Bryman, A. (2012). Social research methods. Oxford: Oxford University Press.

Burhanuddin, 2013. Participative management and its relationship with employee performance behaviour: a study in the university sector in Malang Indonesia. PhD. University of Adelaide. Australia.

Bush, T. and Middlewood, D. (2005). Leading and Managing People in Education. London: Sage.

Creswell, J.W. (2012). Educational research: planning, conducting, and evaluating quantitative and qualitative research. London: Pearson.

Sukkur IBA Journal of Management and Business - SIJMB | Vol 8 No. 1 January - June 2021 
Creswell, J.W. and Plano Clark, V.P. (2011). Designing and conducting mixed methods research. Los Angeles: Sage.

Gizir, S. (2014). A qualitative case study on the organizational identity of faculty members. Educational Sciences: Theory and Practice, 14 (4), pp.1309-1324.

Gmelch, W.H. (2004). The department chair's balancing acts. New Directions for Higher Education, (126), pp.69-84.

Hardré, P.L., Beesley, A.D., Miller, R.L. and Pace, T.M. (2011). Faculty motivation to do research: across disciplines in research-extensive universities. Journal of the Professoriate, 5 (1), pp.35-69.

Kaiser, R.B. and Overfield, D.V. (2010). Assessing flexible leadership as a mastery of opposites. Consulting Psychology Journal: Practice and Research, 62 (2), pp.105-118.

Kalargyrou, V., Pescosolido, A.T. and Kalargiros, E.A. (2012). Leadership skills in management education. Academy of Educational Leadership Journal, 16 (4), pp.39-63.

Kim, H.G. (2011). Job satisfaction among Korean academics: a critical investigation. PhD. University of Nottingham. United Kingdom.

.Kok, S. K., \& McDonald, C. (2017). Underpinning excellence in higher education-an investigation into the leadership, governance and management behaviours of highperforming academic departments. Studies in Higher Education, 42(2), 210-231.

McCaffery, P. (2010). The higher education manager's handbook: effective leadership and management in universities and colleges.2nd ed. London. Routledge.

Middlehurst, R. (1995). Changing leadership in universities. In: N.T. Schulter, ed.The changing university. London: Open University Press.pp.75-92.

Mushtaq, S. and Akhtar, M.A. (2014). Study to investigate the effect of demographic variables on leadership styles used by department heads in universities. Journal of Quality and Technology Management, 10 (1), pp. 17-33.

Nahavandi, A. (2015). The art and science of leadership. Boston: Pearson.

Northouse, P.G. (2013). Leadership: theory and practice. Thousand Oaks, CA: Sage.

Smothers, J., Absher, K. and White, D. (2012). In the eye of the beholder: a configurational analysis of followers' conceptualizations of the ideal academic department leader at private universities. Leadership, 8 (4), pp.397-419.

Toker, B. (2011). Job satisfaction of academic staff: an empirical study on Turkey. Quality Assurance in Education, 19 (2), pp.156-169.

Yukl, G. (2012). Effective leadership behavior: what we know and what questions need more attention. The Academy of Management Perspectives, 26 (4), pp.66-85.

Yukl, G. and Mahsud, R., (2010). Why flexible and adaptive leadership is essential. Consulting Psychology Journal: Practice and Research, 62 (2), pp.81-93. 